\title{
CT-Guided Block and Radiofrequency Ablation of the C2 Dorsal Root Ganglion for Cervicogenic Headache
}

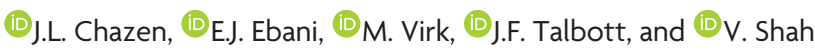

\begin{abstract}
SUMMARY: The purpose of this report is to describe the technical aspects of CT-guided C2 dorsal root ganglion diagnostic block and radiofrequency ablation for refractory cervicogenic headache. CT guidance allows precise and safe positioning of a needle adjacent to the C2 dorsal root ganglion. At-risk neural and vascular structures can be avoided with $\mathrm{CT}$, and it can provide a thorough understanding of upper cervical neuroanatomy.
\end{abstract}

ABBREVIATIONS: DRG = dorsal root ganglion; $\mathrm{RF}=$ radiofrequency

$\mathrm{C}_{\mathrm{f}}^{\mathrm{c}}$ ervicogenic headache is defined as pain referred to the head from the cervical spine or nerve roots. Clinical features are inadequate to isolate the cervical spine as a source of headache, and imaging in conjunction with diagnostic injections is required for a definitive diagnosis. ${ }^{1}$ Osteoarthritis of the lateral atlantoaxial joints is an important consideration in refractory cases resulting from irritation of the $\mathrm{C} 2$ dorsal root ganglion (DRG). Unlike the lower cervical roots, the $\mathrm{C} 2$ nerve root has only sensory components and arborizes to both the greater and lesser occipital nerves. ${ }^{2}$ Patients presenting with pain in the posterior scalp radiating to the vertex may be incorrectly diagnosed with primary occipital nerve entrapment. ${ }^{3}$ Clinical and imaging work-up may reveal irritation of the $\mathrm{C} 2, \mathrm{C} 3$, or $\mathrm{C} 4$ nerve roots, resulting in occipital distribution pain. Herein, we describe the technical considerations of a C2 dorsal root ganglion nerve block and radiofrequency (RF) ablation using CT guidance. Image-guided pulsed or thermal RF ablation of the C2 DRG has been described with high response rates ${ }^{4,5}$; however, the CT-guided technique has not been previously reported, to our knowledge.

Received April 17, 2019; accepted after revision June 13.

From the Departments of Radiology (J.L.C., E.J.E.) and Neurosurgery (M.V.), Weill Cornell Medicine, NewYork-Presbyterian Hospital, New York, New York; Department of Neurosurgery, (M.V.), Center for Comprehensive Spine Care, New York, New York; Department of Radiology \& Biomedical Imaging (J.F.T.), University of California, San Francisco and Zuckerberg San Francisco General Hospital, San Francisco, California; and Department of Radiology \& Biomedical Imaging (V.S,), University of California, San Francisco, San Francisco, California.

Please address correspondence to J. Levi Chazen, MD, Weill Cornell Medicine, NewYork-Presbyterian Hospital, Department of Radiology, 525 East 68th St, Starr 631, New York, NY 10065, 212-746-2578; e-mail: jlc2008@med.cornell.edu; @levichazen

DIndicates article with supplemental on-line video.

http://dx.doi.org/10.3174/ajnr.A6127

\section{Patient Selection}

Complete patient selection criteria are beyond the scope of this technical report; suggested indications and contraindications are outlined in the Table. Briefly, patients should be considered for C2 DRG RF ablation if they present with occipital-distribution pain of a cervicogenic origin and have failed conservative therapy, including medication and physical therapy. An occipital nerve block is often performed initially to exclude a peripheral occipital nerve entrapment. CT and/or MR imaging of the cervical spine should be performed to evaluate the upper cervical nerve roots and facet joints. Classically, an asymmetric pattern of C1-C2 facet osteoarthrosis is seen with loss of cartilage and subchondral sclerosis (Fig 1). Posterior osteophyte formation may narrow the $\mathrm{C} 1-\mathrm{C} 2$ foramen and impinge on the C2 DRG, resulting in occipital neuralgia. Corresponding subarticular bone marrow edema may further suggest the $\mathrm{C} 1-\mathrm{C} 2$ joint as the pain generator (Fig 1).

\section{Technique}

Patients should be placed head first on the CT gantry table in the supine or prone position with the head in neutral alignment facing the ceiling or in slight rotation away from the painful side. Moderate sedation may be offered for patient comfort; however, it is important that the patient remain awake for RF ablation sensory testing. Scout topograms of the craniocervical junction are acquired in the frontal and lateral planes. An axial CT stack can then be prescribed from the skull base through C3. The C2 dorsal root ganglion can be visualized in the axial plane just dorsal to the C2 lateral mass (Fig 2). An adequate CT dose is necessary for visualization, and the authors recommend $120 \mathrm{kV}$ and $100-200$ $\mathrm{mA}$ (diagnostic dose) at $2.5 \mathrm{~mm}$ (reconstructed to $0.625-\mathrm{mm}$ bone and standard algorithms) for the initial preprocedural planning scan. The dose may be reduced to $10-50 \mathrm{~mA}$ for subsequent 
Suggested indications and contraindications for the C2 nerve block and RFA procedure Indications

\begin{tabular}{ll}
\hline $\begin{array}{l}\text { Occipital neuralgia for }>6 \text { weeks } \\
\text { Ipsilateral arthrosis of the lateral } \mathrm{Cl}-\mathrm{C} 2\end{array}$ & $\begin{array}{c}\text { Coagulopathy }(\mathrm{INR}>1.5 \text {, platelets }<50) \\
\text { Known vertebral artery variant crossing at } \mathrm{Cl}-\mathrm{C} 2 \\
\text { facet joint on } \mathrm{CT} \text { and/or MR imaging } \\
\text { with } \mathrm{Cl}-\mathrm{C} 2 \text { foraminal stenosis }\end{array}$ \\
$\begin{array}{l}\text { Lack of response to conservative } \\
\text { management (medication and/or } \\
\text { occipital nerve block) }\end{array}$ & $\begin{array}{c}\text { Contrast allergy } \\
\text { a }\end{array}$ \\
\hline
\end{tabular}

Note:-RFA indicates radiofrequency ablation; INR, international normalized ratio.

${ }^{a}$ Relative contraindication because preoperative noncontrast MRA may be performed.

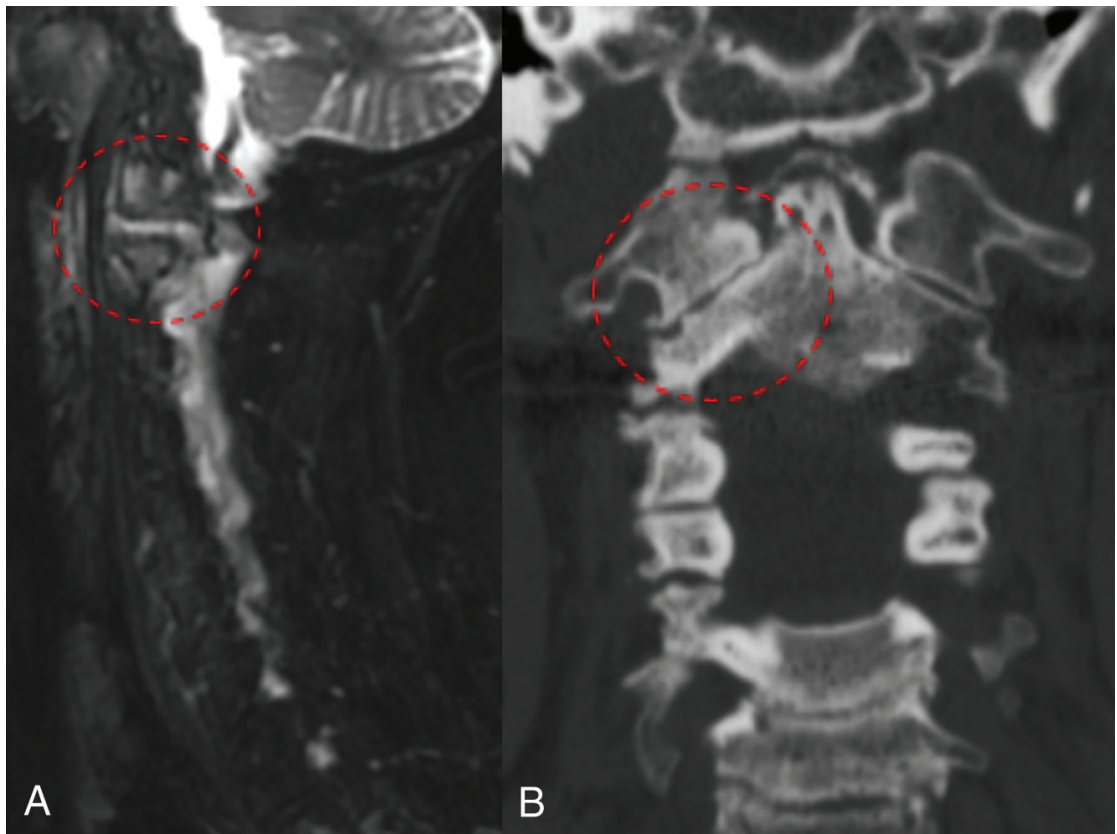

FIG 1. $A$, Sagittal STIR sequence reveals increased T2-hyperintense signal in the right $\mathrm{Cl}-\mathrm{C} 2$ joint and periarticular bone marrow edema (circle). B, Coronal CT scan shows asymmetric marked osteoarthrosis of the right $\mathrm{Cl}-\mathrm{C} 2$ articulation, with loss of joint height, cortical irregularity, and subchondral sclerosis (circle).

procedural scans acquired for needle localization. Serial CT or CT fluoroscopy can be used on the basis of the interventionalist's preference. If preoperative angiography or MR imaging is not available, a targeted CT angiogram may be performed with intravenous contrast. It is important to identify relevant vertebral artery variants that may be present in up to $31 \%$ of patients at the $\mathrm{C} 1-\mathrm{C} 2$ level. ${ }^{6}$ Due to the transient nature of intravenous $\mathrm{CT}$ contrast, the authors recommend that if performed, a procedural CTA scan be obtained once the needle entry site has been selected and the patient's head immobilized because the CTA may be of limited utility if the patient is significantly repositioned (On-line Video).

\section{C2 Nerve Block}

In preparation for needle insertion, the skin is sterilized and buffered $1 \%$ lidocaine is instilled subcutaneously for local anesthesia. A 22-ga, 2.5- to 3.5-inch Quincke-type spinal needle is then inserted. By means of intermittent CT guidance, the needle is advanced to approximate the $\mathrm{C} 2$ dorsal root ganglion. Care should be taken to avoid advancing the needle medial to the DRG, given the close proximity to the dura. If blood is seen in the hub, the needle may be carefully repositioned. There is a rich venous

plexus surrounding the C2 DRG; a small volume $(0.2-0.3 \mathrm{~mL})$ of iohexol (Omnipaque 180; GE Healthcare, Piscataway, New Jersey) 180 or 240 contrast diluted with normal saline should be injected to ensure appropriate positioning and exclude inadvertent arterial or dural puncture. Once the appropriate position is confirmed, a 1- to 2-mL 1:1 mixture of preservative-free dexamethasone, $10 \mathrm{mg} / \mathrm{mL}$, and $0.5 \%$ or $0.75 \%$ of bupivacaine is prepared and slowly instilled through the needle. The needle is then removed with the stylet in place.

\section{Radiofrequency Ablation}

For RF ablation, the authors recommend a 22-ga, 5- or 10-cm-length cannula with a 5-mm uninsulated tip. A grounding pad is placed on the upper thigh. Following the steps described above, an RF ablation canula is substituted for the spinal needle. Once the appropriate position is confirmed on CT, the stylet is removed and the radiofrequency probe is inserted (Fig 3). Impedance levels should be checked and are typically $<300 \Omega$. Sensory testing is then performed at $50 \mathrm{~Hz}$ up to $2 \mathrm{~V}$. Pain should be elicited in the distribution of the ipsilateral occipital nerve. Motor testing at $2 \mathrm{~Hz}$ may then be performed, which may evoke mild local contraction of the paraspinous musculature. Then, $0.5 \mathrm{~mL}$ of unbuffered $1 \%$ lidocaine is instilled in the RF cannula, and a CT scan is obtained with the RF probe in place for final confirmation of positioning. Thermal RF ablation is then performed at $80^{\circ} \mathrm{C}$ for 90 seconds. The patient may experience local discomfort during the thermal ablation and should be encouraged to hold still for the duration of the ablation. Discomfort during the ablation typically improves as the ablation continues. If the pain is severe and/or persistent, the ablation should be stopped and the needle withdrawn slightly before re-ablating, or alternatively, pulsed radiofrequency ablation may be considered. If pulsed RF ablation is desired, identical treatment steps may be followed, but the RF generator should be set to pulsed $\mathrm{RF}$ at $42^{\circ} \mathrm{C}$ for 120 seconds.

Following RF ablation, the probe is removed and a nerve block can be performed through the canula with dexamethasone and bupivacaine as described above to decrease postprocedural inflammation and discomfort. The canula is then removed with the stylet in place, and a sterile bandage is applied. Patients may experience a flare of symptoms for 24-72 hours following thermal RF ablation; oral nonsteroidal anti-inflammatory drugs are generally adequate for pain control. In cases of severe postoperative pain inadequately controlled with nonsteroidal anti-inflammatory drugs, a methylprednisolone 


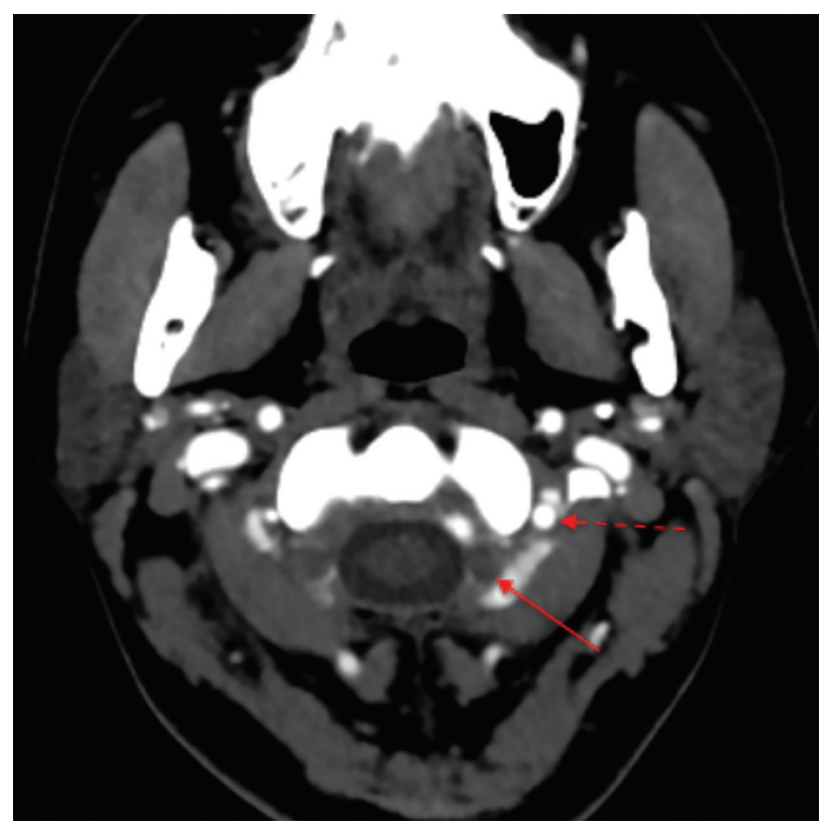

FIG 2. Axial $C T$ angiogram showing the left $\mathrm{C} 2$ dorsal root ganglion (arrow) positioned behind the left C2 lateral mass. The left proximal V3-segment vertebral artery is highlighted (dashed arrow) anterolateral to the target.

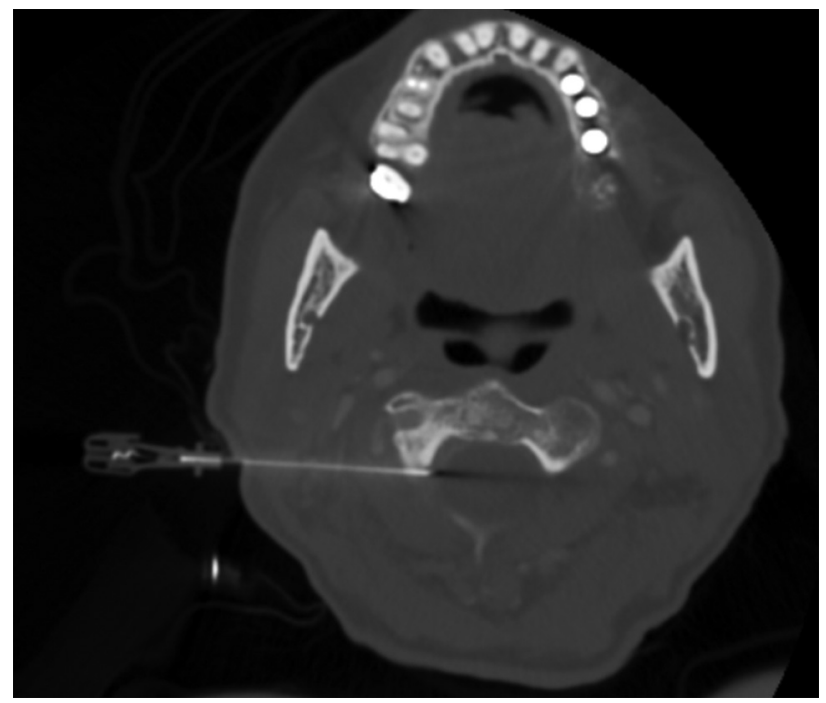

FIG 3. Intraprocedural axial CT scan showing appropriate placement of a 5-cm RF cannula targeting the right C2 DRG.

(Medrol) dose pack may be helpful to decrease inflammation and discomfort.

\section{DISCUSSION}

Cervicogenic headache has an estimated prevalence of up to $4.1 \%$ of the general population and up to $20 \%$ in patients with chronic headache. ${ }^{7-9}$ Image-guided injection of the upper cervical spine has been described for treatment of cervicogenic headache, including the atlanto-occipital, atlantoaxial, C2-C3, and C3-C4 facet joints and nerve blocks of $\mathrm{C} 1$ through $\mathrm{C} 4$. The $\mathrm{C} 2 \mathrm{DRG}$ is the principal nerve root supplying the greater and lesser occipital nerves and provides an ideal target for direct neurolysis. The corridor for needle insertion is generally safe, lying at the axial level of the proximal V3-segment vertebral artery where it traverses anterolateral to the C2 DRG (Fig 2). Vascular variants such as an inferior course of the PICA may be problematic in cases of dural puncture at the C1-C2 level but should not affect the epidural C2 DRG injection. ${ }^{10}$ However, intraprocedural CT angiography can be performed to ensure a safe procedural approach because head positioning may alter expected axial anatomy.

Pulsed RF can be considered in place of thermal RF and has advantages including a decreased potential for local thermal injury and a decreased incidence of postprocedural inflammation. However, the pulsed RF procedure is potentially less efficacious than thermal RF. Patients may experience a shorter duration of pain relief compared with thermal RF, necessitating repeat procedures.

Complications from C2 RF ablation are uncommon and usually present as numbness and dysesthesia following neurotomy. However, in the largest described case series of thermal C2 RF ablation, $>90 \%$ of patients reported that they would undergo the procedure again if pain returned. ${ }^{4}$ Some authors advocate sacrificing the $\mathrm{C} 2 \mathrm{DRG}$ during surgical $\mathrm{C} 1-\mathrm{C} 2$ fusion because numbness often has no effect on health-related quality of life, unlike neuralgia. ${ }^{2}$ A meta-analysis of radiofrequency ablation for cervicogenic headache yielded mixed results but covered a heterogeneous population with a variety of targets, image-guidance modalities, and RF techniques. ${ }^{8}$ Potential risks of the procedure include intra-arterial or intrathecal puncture and injection of medication. The risks of intrathecal puncture include spinal fluid leak or spinal cord puncture. The implications of intrathecal injection include nontarget injection (false-negative response from the nerve block), high spinal block, and arachnoiditis. Implications of an intra-arterial injection include a nontarget injection and spinal cord or posterior fossa infarct from intra-arterial injection of steroids. Although ischemic complications of intra-arterial injection have not been reported with nonparticulate steroids in the cervical spine, the authors recommend using preservative-free dexamethasone in all cases. Anecdotally, the thermal RF procedure has excellent sustained results and may obviate morbid upper cervical fusion, but further prospective study is needed to confirm these observations.

\section{CONCLUSIONS}

CT provides excellent guidance for $\mathrm{C} 2 \mathrm{DRG}$ injection and radiofrequency ablation and can be combined with procedural CT angiography to highlight vascular anatomy.

Disclosures: Michael Virk—UNRELATED: Consultancy: Globus Medical, Depuy Synthes, Brainlab.

\section{REFERENCES}

1. Bogduk N. The neck and headaches. Neurol Clin 2014;32:471-87 CrossRef Medline

2. Janjua MB, Zhou PL, Greenfield JP, et al. C2 and greater occipital nerve: the anatomic and functional implications in spinal surgery. Cureus 2017;9:e1074 CrossRef Medline

3. Bogduk N, Govind J. Cervicogenic headache: an assessment of the evidence on clinical diagnosis, invasive tests, and treatment. Lancet Neurol 2009;8:959-68 CrossRef Medline

4. Hamer JF, Purath TA. Response of cervicogenic headaches and occipital neuralgia to radiofrequency ablation of the $\mathrm{C} 2$ dorsal root

AJNR Am J Neuroradiol 40:1433-36 Aug 2019 www.ajnr.org 
ganglion and/or third occipital nerve. Headache 2014;54:500-10 CrossRef Medline

5. Zhang J, Shi DS, Wang R. Pulsed radiofrequency of the second cervical ganglion $(\mathrm{C} 2)$ for the treatment of cervicogenic headache. J Headache Pain 2011;12:569-71 CrossRef Medline

6. Katoh $\mathrm{Y}$, Itoh $\mathrm{T}$, Tsuji $\mathrm{H}$, et al. Complications of lateral C1-2 puncture myelography. Spine (Phila Pa 1976) 1990;15:1085-87 CrossRef Medline

7. Haldeman S, Dagenais S. Cervicogenic headaches: a critical review. Spine J 2001;1:31-46 CrossRef Medline
8. Nagar VR, Birthi P, Grider JS, et al. Systematic review of radiofrequency ablation and pulsed radiofrequency for management of cervicogenic headache. Pain Physician 2015;18:109-30 Medline

9. Grandhi RK, Kaye AD, Abd-Elsayed A. Systematic review of radiofrequency ablation and pulsed radiofrequency for management of cervicogenic headaches. Curr Pain Headache Rep 2018;22:18 CrossRef Medline

10. Brinjikji W, Cloft $\mathrm{H}$, Kallmes DF. Anatomy of the posterior inferior cerebellar artery: relevance for $\mathrm{C} 1-\mathrm{C} 2$ puncture procedures. Clin Anat 2009;22:319-23 CrossRef Medline 